\title{
LECTURAS SOBRE LA CULTURA ESPAÑOLA EN EL SIGLO XVIII FRANCÉS
}

\author{
José Checa Beltrán
}

Centro de Ciencias Humanas y Sociales (CSIC)

\section{INTRODUCCIÓN. NACIONALISMO, CANON E IDEOLOGÍA}

Estas páginas se ocupan de examinar la imagen de la cultura española en la Francia del xviII, de analizar las "lecturas" que los letrados franceses de la época hicieron de nuestro país. En la historiografía al uso domina la idea de que la Francia del siglo ilustrado no solo mantuvo vigente la supuesta leyenda negra antiespañola, sino que despreció a España, ignorando o subestimando su legado histórico, y manifestando poco interés por conocer la actualidad de su cultura. Según mis investigaciones, estas opiniones merecen una rectificación.

La historiografía ha repetido y subrayado las negativas opiniones sobre el papel histórico-cultural de España que expresaron Montesquieu, Voltaire o algunos otros autores franceses, así como la enorme carga negativa del imaginario francés sobre España. ${ }^{1}$ Hay mucho de cierto en

${ }^{1}$ Por citar solo una fuente que resume ese imaginario, digamos que Lydia Vázquez (1997: 426) concluye que "les philosophes et écrivains français" del xVIII estimaban que los españoles (y también los portugueses) eran "superstitieux, insensibles aux raffinements des arts et des lettres, ne sachant composer que de mauvaises comédies (et ce, malgré leur passé littéraire glorieux) et des couplets à chanter devant les rejas des fenêtres, bigots, Portugais et Espagnols sont des représentants de nations opposées par tradition aux Lumières, comme le montrent les nombreux et atroces autodafés qui ont lieu en terres péninsulaires. Ce n'est pas pour rien qu'ils ont été appelés les 'cafres' de l'Europe". 
que los "philosophes" franceses fueron muy críticos con España, a quien se asimilaba invariablemente con la Inquisición, el fanatismo eclesiástico, la superstición, la crueldad en las colonias americanas, etc. Sin embargo, no existen estudios monográficos sobre la existencia de corrientes de opinión francesas reconocedoras del papel histórico de España y de sus aportaciones a la cultura occidental. Tampoco existen, que sepamos, estudios sobre la existencia de medios franceses interesados en establecer canales de comunicación con los españoles. Indagar en esa línea es objetivo de este trabajo.

En los últimos años he tenido la oportunidad de examinar un buen número de textos dieciochescos franceses que, creo, nunca habían sido analizados con la citada perspectiva y que, como digo, desmienten o puntualizan esa idea de una Francia absolutamente despreciativa con todo lo español. Todo lo contrario se desprende de algunos importantes periódicos y libros franceses de la época, que demuestran la existencia de una corriente francesa reconocedora del legado cultural español, coexistente con otra, la de los "philosophes", muy crítica al respecto. Ello no significa que los autores favorables a España militasen en el campo de la antifilosofía o de la reacción política. En general, militaron en el campo reformista, algunos fueron masones y compartieron en gran medida el pensamiento enciclopedista. Pero su carácter independiente, su cercanía al gobierno y el hecho de no pertenecer a grupos de poder "filosóficos", le alejaron de estos, con quienes algunos mantuvieron sonadas polémicas. Caso aparte es el de las Mémoires de Trévoux, cuyo acercamiento a España se produjo en unos años en que el filosofismo aún no había cobrado fuerza en Francia.

A falta de ulteriores investigaciones que amplíen y profundicen mi campo de análisis, podemos sostener que en el siglo XVIII francés hubo ciertos periódicos interesados en mantener contactos con la intelectualidad española, bien predispuestos para enjuiciar el legado de nuestro país, bastante elogiosos con la aportación cultural española y críticos con sus compatriotas "philosophes" por su desinterés o excesivo rigor en sus juicios sobre el legado histórico español. ${ }^{2}$ He estudiado para este trabajo los siguientes:

\footnotetext{
${ }^{2}$ Sin embargo, y en contra de la opinión historiográfica más extendida, la profesora Étienvre muestra en las páginas de este libro cómo Voltaire fue con respecto a España menos crítico de lo que siempre se ha dicho.
} 
Mémoires de Trévoux. Memoires pour (servir a) l'histoire des Sciences et des Beaux-Arts, 1701-1767).

Journal étranger (1754-1762).

L'année littéraire (1754-1790).

L'Espagne littéraire (1774).

Además, existen otros periódicos de la época en que se dieron noticias de España sin reseñables prejuicios en contra: por ejemplo $\mathrm{La}$ Gazette Littéraire de l'Europe (1764-1766), Variétés Littéraires, (1768-1769), o Nouvelles de la république des lettres et des arts, publicado entre 1777 y 1788 (Étienvre 1973). ${ }^{3}$

De gran interés son los vínculos que existen entre los editores de tres de estos periódicos, Journal Étranger, L'Espagne littéraire y L'Année littéraire, cuyas líneas editoriales comparten explícitamente su positiva estimación sobre el legado español, así como la conveniencia de darlo a conocer en Francia.

Pero no solo en la prensa hallamos esa actitud favorable a España: la Bibliothèque universelles des romans (1775-1789) hace una extensísima apología de la producción novelística española. Modelo de ecuanimidad es el Tableau de l'Espagne Moderne, de J. Fr. Bourgoing, que gozó de varias ediciones en francés en el paso del siglo XVIII al XIX. Entre otros, L.S. Mercier supo reconocer algunos méritos del legado "barroco" español en De la littérature et des littérateurs (1778). ${ }^{4}$

El carácter sintético de las próximas páginas no me permitirá detenerme en algunas cuestiones que merecerían un mayor desarrollo: por ejemplo, el desconocimiento francés del legado español era mayor por lo que respecta a la producción española de las útimas décadas del siglo XVII y siguientes. En efecto, la aportación cultural de España en su

\footnotetext{
${ }^{3}$ La profesora Étienvre ha estudiado este periódico desde la perspectiva que aquí nos interesa. En él aparecen más noticias sobre España que en L'Année littéraire y el Journal étranger; sin embargo, son simplemente noticias sobre el ámbito cultural español, sin comentarios al respecto (1973: 328). Con posterioridad al asunto Masson, las Nouvelles demostraron su simpatía por la causa española (1973: 331).

${ }^{4}$ Naturalmente, existen otros textos favorables a España mejor conocidos por la historiografía. Entre otros, el libro de Jean de Vayrac, Etat présent de l'Espagne (1719), cuya descripción geográfica e histórica de España es claramente apologética; escrito contra "algunos autores modernos" que "en parlant des moeurs et des usages du Gouvernement des Espagnols" le atribuyen defectos que no tiene. Asimismo, sus opiniones sobre las costumbres y el carácter de los españoles es muy positiva.
} 
etapa de gran potencia mundial era más conocida y apreciada en Francia. Por otra parte, la comunicación francoespañola creció paulatinamente durante el siglo XVIII.

Asimismo, es innegable que cuando la Francia del siglo XVIII dirigía su mirada al extranjero, estaba interesada principalmente en Inglaterra, menos en Italia y Alemania, y algo menos aún en España. ${ }^{5}$ Finalmente, el hecho de que muchos autores franceses del xvIII conocieran y enjuiciaran las aportaciones culturales españolas consolida la idea de la existencia de una cultura europea común, cuyo sustrato colectivo no se diluye porque una nación antes fuerte entre en decadencia, ni desaparece por disensiones ideológicas o guerras. Junto a las discrepancias coyunturales, los distintos países participan de un legado común europeo, cuya valoración sufre los vaivenes derivados de la política o de los cambiantes gustos estéticos, pero cuya existencia y difusión en Europa permanece a los largo de los siglos.

Nuestro examen será muy sintético y tendrá un doble propósito. Primero: el de subrayar que en la construcción de un imaginario nacional (aunque en cada nación puedan coexistir diversos imaginarios, como es nuestro caso) juegan un papel determinante tres elementos: un omnipresente nacionalismo político-cultural, el canon estético dominante en cada país, así como la ideología e intereses particulares de los distintos escritores. Segundo: el de ilustrar estas páginas, aunque brevísimamente, con diversos ejemplos relativos a la positiva recepción francesa del legado español, muy desconocida hasta ahora.

Obviamente, en tan pocas páginas no puede darse cuenta detallada de un asunto tan complejo, cuyos diferentes aspectos necesitarían ser investigados de manera monográfica, atendiendo a cuestiones como la cambiante relación diplomática entre ambos países, las variaciones en el paradigma estético, las alteraciones en la ideología e intereses coyunturales de los autores, etc. Me conformaré, por el momento, con ofrecer un panorama general lo más representativo posible, y ofreceré en publicaciones posteriores detalles más precisos de cuanto aquí presento de manera panorámica y resumida.

\footnotetext{
${ }^{5}$ Todo ello dependía, lógicamente, del ámbito cultural al que Francia dirigía su mirada. Por ejemplo, Italia fue una referencia de primer orden en el campo de la música y las bellas artes.
} 


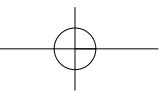

Permítaseme una última reflexión antes de comenzar mi exposición: el llamado "imaginario nacional" sobre otra nación supone una representación que condensa sucesivas "lecturas" históricas - determinadas por la relación política, militar y cultural entre países-, que en cada momento encarnan la opinión mayoritaria de un país sobre otro. Una opinión que incluye valoraciones sobre la historia, el legado cultural y el carácter de una nación. Para empezar, he de subrayar que en casi todos los textos franceses que he leído (incluidos los favorables a España) subyace la idea, más o menos explícita, de que España ha estado dominada históricamente por la Iglesia y la Inquisición, con resultados nefastos para sí misma y su entorno. Pero, como digo, además de esta idea existen en muchos textos estimaciones muy positivas sobre la contribución española al legado occidental. Opiniones, como he adelantado, pasadas por el filtro nacionalista, estético e ideológico. Los textos examinados pertenecen preferentemente al ámbito literario-cultural, aunque su significado solo podrá entenderse situándolos en su marco político y social.

Obviamente, su grado de nacionalismo dependerá de la lucidez, objetividad, cultura, capacidad autocrítica e intereses personales de cada autor, pero merece subrayarse que el nacionalismo está presente incluso en los letrados más cosmopolitas, autocríticos y abiertos al exterior. En nuestro caso, habremos de referirnos en este punto a la conocida como "leyenda negra".

Por otra parte, cada país profesa mayoritariamente un canon cultural que, aunque en determinados momentos históricos sea parecido al del grupo de países de su entorno, siempre posee caracteres propios que lo distinguen. En nuestro caso, y concretamente en los ámbitos literario y artístico dieciochescos, podríamos señalar el acendrado clasicismo de la cultura institucional francesa, frente a las vacilaciones españolas entre un canon barroco o neoclásico.

Finalmente, como elemento decisivo que aglutina y personaliza los anteriores, hallamos la ideología, militancia política e intereses personales de cada autor. Ello condiciona e individualiza decisivamente las "lecturas" de cada autor.

Obviamente, cuando la actitud ante España es negativa por motivos ideológicos ya a priori, el canon y el nacionalismo refuerzan el descrédito del legado cultural español. Por otro lado, hasta los autores franceses mejor predispuestos con España modificaron esa buena pre- 
disposición cuando en sus juicios interfieren cuestiones de gusto y patrióticas.

Considero que dichos elementos deben ser sopesados en la presente investigación, cuyo objetivo es, como digo, mostrar que, en contra de la historiografía al uso, en la Francia del siglo xvIII existió una corriente de acercamiento a España que valoró el legado cultural español y que estuvo interesada en crear redes de contactos que permitieran a los franceses conocer mejor la historia cultural y literaria de España, así como las novedades literario-culturales que iban apareciendo en nuestro país.

\section{Canales de COMUnicación}

Como apuntábamos, muchos autores franceses conocen relativamente bien la cultura española hasta mediados del siglo XVII, pero no sucede igual con la producción española de finales del XVII y del siglo XVIII, que es deficientemente conocida. Asimismo, existen en la Francia del XVIII autores con escaso interés por mejorar su conocimiento del legado histórico español, por ejemplo los "philosophes". Pero también existen, como sostengo en este trabajo, letrados franceses del siglo ilustrado que enjuician ese desinterés como una limitación para Francia; se lamentan del desconocimiento que existe en su país de la cultura española reciente y consideran conveniente una mejor información al respecto. Se quejan también de que muchos escritores franceses enjuicien negativamente la literatura castellana cargados de prejuicios y sin apenas conocerla.

Existen, así pues, en la Francia del xvIII medios periodísticos y autores verdaderamente interesados en acercarse a España, mediante la traducción de obras españolas y el establecimiento de contactos permanentes para estar al día de su producción intelectual. Su actitud es verdaderamente cosmopolita, desprejuiciada, con un auténtico deseo de conocer lo que se publica en otros países, lo cual no es tan fácil si no cuentan en ellos con corresponsales. Por ello, esos periódicos manifiestan explícitamente, como vamos a comprobar, su deseo de mantener corresponsales en España que les mantengan bien informados de sus novedades editoriales y sus acontecimientos culturales. 
Disponemos de numerosas pruebas sobre las deficiencias en la comunicación cultural francoespañola durante la primera mitad del siglo XVIII. Muestra de ello es la reseña que en 1747 (VIII, 1432-1441) publicaron las Mémoires de Trévoux acerca de la Carta latina de Ignacio Philalethes a los P.P. de Trévoux sobre lo que se dice en las Memorias del mes de marzo de 1742 acerca de las cosas literarias de España (Zaragoza, 1743). El hecho de que esta Carta, escrita por Luzán y en la que los memorialistas estaban directamente concernidos y criticados, se publicara en España en 1743 y de que los franceses solo tuvieran conocimiento de ella cuatro años después, es sintomático de la falta de agilidad en la exportación de noticias culturales de España a Francia (no sucedía así en el caso contrario).

Los memorialistas se lamentan de ello. Dicen que solo ahora (en 1747) han tenido conocimiento de este escrito publicado en España hacía ya cuatro años. Esto justifica, dicen, lo que ellos mismos afirmaban en marzo de 1742 (XXII, 1432): que los franceses "sommes communément assez peu instruits de ce qui concerne la littérature d'Espagne" [contemporánea].

Los monjes franceses, deseosos de acabar con esa incomunicación, desean mantener con España una comunicación permanente: "Finissons par un projet de paix entre nos Mémoires et tout ce qu'il y a de gens de lettres dans les Royaumes d'Espagne. Les conditions du traité seraient que des deux côtés" haya estima y cortesía. Según ese acuerdo, los sabios españoles procurarían a los autores de Trévoux los medios para conocer las obras que se impriman más allá de los Pirineos, las cuales serían reseñadas por los periodistas franceses con tanto cuidado como equidad. ${ }^{6}$

A propósito de esta necesidad de canales de comunicación, las Mémoires de Trévoux publican otra reseña (1753: XV, 2685-2704) sobre un libro editado por David Clément, Specimen bibliothecae hispano-majansianae, o Idée d'un Catalogue critique des Ecrivains Espagnols. Dice el reseñador que los bibliográfos de todo el mundo necesitan unos de otros para darse a conocer los libros raros que les interesan. "M.Clément a su qu'il y avait en Espagne un docte personnage qui s'était fait une belle et nombreuse collection de livres; il a recherché sa connoissance, et l'union a

\footnotetext{
${ }^{6}$ Era lógico, por otra parte, que los jesuitas franceses tuvieran esa buena disposición con la patria de San Ignacio, donde, por ejemplo, monjes de su orden eran confesores de los reyes.
} 
été bientôt faite. Ce Savant est d. Gregorio de Mayans", del que, dice, ya hemos hablado con ocasión de la Biblioteca de Escritores del Reino de Valencia.

En el Journal étranger (1760: enero janvier, XXXVI) se dice que en este periódico desean dar a conocer a los buenos escritores y hombres célebres de todas las naciones, por lo que instan a sus "voisins" "à nous faire parvenir des Mémoires" y retratos de hombres ilustres. La respuesta desde España llega en una carta anónima datada el 13 de febrero de 1760 y escrita probablemente por quien va a ser el corresponsal español, Gaspar de Montoya (Pageard 1959: 388 y 393). Publicada en mayo de 1760 ("Lettre sur la Littérature Espagnole", 188-202) y dirigida a los editores del periódico, el autor dice que no puede informar de todas las obras que se publican en España, pero sí de las que pueden servir para que en Francia se conozca mejor al país vecino.

Sin embargo, es cierto que muy avanzado el siglo xviII, y a pesar del esfuerzo de algunos medios franceses por acercarse a la cultura española, España seguía siendo en Francia menos conocida que otros países europeos, lo que equivale a decir que se le había prestado menor atención. En 1774 (I, 2), en el Prospectus de l'Espagne littéraire, con que se inicia esta publicación dedicada a España y a Portugal, se dice que en Francia se han traducido y se conocen las mejores obras de Inglaterra, Italia y Alemania, pero "une seule mine nous restait à exploiter", la de la literatura española, bien digna de "fixer nos regards et d'interesser notre curiosité".

L'Espagne littéraire publica (1774, IV, 3-22) un texto donde el corresponsal en España del periódico (M. d'Arévalo) subraya que la literatura española fue en los siglos pasados muy bien acogida por los autores franceses, que no desdeñaban beber de ella, "d'y puiser". Es un hecho que la lengua española estaba de moda, no solo en Francia "mais ailleurs". Después, cuando el español ha pasado de moda y no se usa el latín, todo ha cambiado, "les canaux de Communications ont été interceptés" y las producciones de los españoles no se exportan. Por eso en Francia se las ignora y se cree que no existen. De ahí la necesidad de restablecer los antiguos canales de comunicación.

En este artículo se da una explicación política a la escasa presencia de España en la Francia y la Europa contemporáneas. El hecho es que la literatura española no es suficientemente estimada hoy por las otras naciones: “quelques changements dans l'Ordre politique de l'Europe 
ont pu y contribuer"; cuando reinaba en España la Casa de Austria y poseía en Europa amplios territorios, la literatura española estaba más extendida. Los españoles frecuentemente imprimían sus obras en Milán, Nápoles, Bruselas, Amberes, Ámsterdam, etc. Ahora todo ha cambiado, pero es necesario restablecer una comunicación fluida con España.

El deseo de instituir canales con España se advierte también en la Bibliothèque universelle des romans, donde el editor (1776: juillet, premier volume, III, 1-17) solicita ayuda para acceder al conocimiento de la novela española contemporánea, peor conocida que la de siglos pasados: "nous ne sommes pas en état de nous expliquer sur l'état actuel des Romans en Espagne. Nous ne savons à quel genre les Auteurs modernes de fiction s'attachent aujourd'hui, et s'il y a même de la fertilité chez eux. Nous serions reconnaissants si l'on voulait nous donner des éclaircissemens à ce sujet. Ils rendraient plus utile et plus abondant l'usage que nous nous proposons de faire des Romans de cette Nation, et contribueraient beaucoup au plaisir et à l'instruction de nos lecteurs".

Así pues, si bien es constatable la escasez de canales de comunicación entre España y Francia durante gran parte del siglo XVIII, también es evidente el interés de ciertos medios franceses por entablar contactos. Ello iba acompañado de una actitud muy positiva en sus "lecturas" del legado español.

\section{Elogios al legado español. Deudas francesas con España}

La buena predisposición hacia España de ciertos medios periodísticos franceses incluye el reconocimiento de sus pasados méritos culturales y científicos, así como de sus progresos contemporáneos. Para los críticos franceses, normalmente de gusto clasicista, los principales logros de los españoles en el ámbito literario son aquellas obras que se enmarcan en esa estética. Pero, además, esos críticos se muestran muy comprensivos y elogiosos con obras españolas que escapan a ese gusto.

En el campo del pensamiento literario, el decidido clasicismo de la Poética de Luzán proporciona a las Mémoires de Trévoux la oportunidad de hacer una sincera y consistente apología de una obra española. En 
efecto, en $1748^{7}$ (995-1027; 1248-1280; 1438-1471) publicaron una larga reseña sobre este tratado de Luzán, con enfáticos elogios para el autor español, cuyos principios literarios coincidían con el clasicismo francés y cuya obra supuso una gran sacudida antibarroca en las mentes de los españoles. "L'Ouvrage que nous annonçons au Public est le fruit d'une lecture immense et d'une étude profonde. Il semble que $\mathrm{M}$. de Luzan soit de tous les Pays de l'Europe, tant il est au fait de la littérature de chaque peuple. Il en connaît tous les bons Auteurs", exceptuando los ingleses. "Pour l'honneur de M. de Luzan, nous souhaiterions que la Langue Espagnole fût aujour-d'hui à la mode en France. Il ne manque à cet Ouvrage que des Lecteurs". Y acaban felicitando "très sincèrement l'Espagne d'avoir produit un Art Poétique aussi parfait que celui de M. de Luzan" (996-998).

Como pueba de una España actualizada en el conocimiento científico, las Mémoires de Trévoux (1753: 2925-2929) reseñan una obra titulada Thèses de philosophie spéculative et expérimentale, soutenue dans l'Université de Cervera, publicada en Cervera, en 1753, sin nombre de autor. Estas tesis, se dice, nos instruyen del estado de las ciencias filosóficas en España: "le goût de la nouvellle Philosophie y perce sensiblement; à l'Electricité près, on y trouve les systèmes et les découvertes les plus récentes...". Se conoce a Newton y se le estima - dice el recensionista - sin mirarlo como el oráculo de la Naturaleza. Se dice que el autor español ha incluido en su obra la historia de todas las sectas filosóficas, y demuestra que le atrae especialmente la Física.

El articulo "Inventions dues aux Espagnols dans différents genres" (1774: II, 83-99) es una muestra del reconocimiento del periódico L'Espagne littéraire a las aportaciones españolas a la ciencia y las letras: tomando como base un artículo del Teatro Crítico de Feijoo sobre este tema, enumera y explica algunos descubrimientos que los españoles han hecho en navegación, máquinas mineras, medicina, etc., así como el carácter modélico de sus libros en el ámbito del Derecho y la Historia. La conclusión es: "et que d'autres Nations se sont attribuées pour la plupart, sans faire nulle mention des premiers inventeurs", los españoles.

\footnotetext{
${ }^{7}$ Nótese que han pasado once años entre la publicación de la Poética (1737) y la aparición de esta reseña en las Mémoires, muestra de las carencias en la comunicación entre ambos paises.
} 
L'Espagne littéraire insiste en la positiva evolución que ha experimentado España en las últimas décadas. Sus ciudades, el carácter de sus habitantes, sus costumbres, sus progresos culturales, etc. Sus academias y sociedades literarias no son inferiores a las francesas, los españoles son graves, confiados y solidarios, el espíritu industrioso de sus habitantes se ha desarrollado, también la limpieza y belleza de sus ciudades y casas, España cuida las artes, el comercio y la industria, etc. En el primer número de L'Espagne littéraire (1774: I, 18-35) aparece un artículo titulado "Lettres Espagnoles pour l'instruction des étrangers", escrito por el corresponsal del periódico en España, don Pedro Pérez de Arévalo. Allí se dice que "Madrid est devenue une des Villes les plus propres de l'Europe. Toutes ses rues sont larges, droites bien alignées; les maisons spacieuses et commodes". El comercio exterior e interior de España "s'accroît de jour en jour". Aparecen también elogios a las distintas Academias españolas: la de la Lengua, de Historia, de Medicina, de Bellas Artes.

Este periódico se erige como defensor de la imagen de España al hacerse eco (1774: IV, 346-350) de una publicación en forma de cartas escritas desde Madrid en los años 1760-1761 por el doctor Clarke, de la Universidad de Cambridge, que vivió en España durante dos años. El articulista dice que en estas cartas - muy críticas - , sobre las finanzas, marina, agricultura, comercio etc. en España, no ha encontrado ningún detalle que no sea o falso en el fondo, o desfigurado por su autor. Cuando Clarke habla de literatura española lo hace casi siempre de manera negativa, a pesar de haber reconocido que solo conoce la lengua española de manera superficial. Todo ello demuestra la ignorancia del autor inglés, que comete un gran número de errores e inexactitudes.

Además, esta publicación muestra su constante preocupación por que los libros españoles sean traducidos o conocidos en Francia. Así sucede, por ejemplo, cuando se reseña la Historia literaria de España de los Mohedano. El recensionista escribe: “elle mériterait bien l'honeur de la traduction" al francés (1774: IV, 138).

La defensa de los progresos españoles se sigue registrando en los años ochenta. En un discurso de Claude Camille François, titulado “Discours sur l'histoire, le gouvernement [...] de plusieurs nations de l'Europe", y publicado en L'Année littéraire (1783: I, 190-209) se dice que "Le Roi d'Espagne, qui non content de vouloir le bien, cherche encore à le faire, a réprimé beacoup d'abus". Para disipar la ignorancia y 
eliminar las malas costumbres en su imperio, ha instituido una 'Sociedad de amigos de la Patria', cuyo fin es favorecer la agricultura, las artes y los oficios. Gracias a él se han construido puentes, canales, caminos, etc. Además, y ello prueba la ideología reformista del periódico, el autor francés dice que el rey se ha rebelado contra los fastos de los señores de la corte, contra los derechos de los grandes de España.

En la Bibliotheque universelle des romans (1781: novembre, 3-40), a propósito de El Conde Lucanor, junto a notables elogios a esta obra y a su autor se escribe: "Nous ne pouvons nous refuser au plaisir d'observer ici, que, dans un temps où la Noblesse de L'Europe se piquoit du singulier mérite de ne savoir pas signer son nom, il y avoit en Espagne de grands Seigneurs, des Princes du Sang et des Rois qui faisaient des livres".

El Tableau de l'Espagne Moderne de Bourgoing es una de las obras francesas que más espacio dedica a comentar, con una gran objetividad, el carácter y las aportaciones culturales y políticas españolas, dedicando una especial atención a los cambios que se registran en la segunda mitad del siglo XVIII. Bourgoing habla de los prejuicios con que se ha enjuiciado a España. Y sostiene que el progreso, aunque lento, de las luces y de la filosofía bien entendida, ha dulcificado sensiblemente las costumbres. Las huellas de la antigua barbarie desaparecen sucesivamente (1807: II, 335). En efecto, J. Fr. Bourgoing comienza su excelente Tableau de l'Espagne Moderne explicando que su objetivo es rectificar errores y prejuicios "dont l'Espagne est encore l'objet pour le reste de l'Europe" (1807: I, V). No quiere ofender a España ni a la verdad, motivo por el que estará en guardia con el tono de sus elogios y de sus sátiras (1807: I, VIII-XIX).

El propio Voltaire, en un artículo titulado "Anecdotes sur Le Cid", publicado como anónimo ${ }^{8}$ en Variétés littéraires (1768-1769), defiende la generosidad de los españoles frente a la envidia de los franceses, que criticaron a Corneille por sus faltas a las reglas y a la moral:

Cependant les auteurs espagnols n'essuyèrent aucun reproche, et les ennemis de Corneille l'accusèrent de corrompre les moeurs. Telle est parmi nous la fureur de l'envie. Plus les arts ont été accueillis en France, plus ils

\footnotetext{
${ }^{8}$ Pageard lo atribuye a Voltaire (1959: 398): se trata de un artículo que se publicó primero en La Gazette littéraire de l'Europe (1764: juillet, II, 229) y después en las Variétés littéraires (1768-1769), de Arnaud y Suard.
} 
ont essuyé de persécutions. Il faut avouer qu'il y a dans les Espagnols plus de générosité que parmi nous. On ferait un volume de ce que l'envie et la calomnie ont inventé contre les gens de lettres qui ont fait honneur à leur patrie (Variétés 1804: III, 274-282).

Voltaire también manifestó su reconocimiento por la cultura española de tiempos pasados. En su Ensayo sobre las costumbres sostiene que los españoles tuvieron una clara superioridad sobre los demás pueblos: su lengua se hablaba en París, en Viena, en Milán, en Turín; "sus modas, sus formas de pensar y de escribir, subyugaron a las inteligencias italianas y, desde Carlos V hasta el comienzo del reinado de Felipe III, España tuvo una consideración de la que carecían los demás pueblos" (Perez 2010: 46).

Son innumerables las ocasiones en que bastantes autores franceses reconocen las copias, imitaciones o deudas de la literatura francesa con respecto a la española, sobre todo en el ámbito del teatro y de la novela. A veces consideran que los originales españoles son más valiosos que las copias francesas, y a veces estiman lo contrario. Pero en todos los casos reconocen en las obras españolas valores como la imaginación y el genio. En general, sitúan las principales aportaciones culturales de España durante el siglo xvi y parte del xviI, época en la que reconocen que España fue un modelo digno de seguir.

Una de las publicaciones que más contribuyó en Europa a la dignificación literaria de la novela como género literario fue la Bibliothèque universelle des romans, que se publicó en 112 tomos entre 1776 y 1789. En ella se trataba de novelas francesas, pero también de las extranjeras vertidas al francés, y contiene una clara apología de la novelística española, en muchos casos de la traducida al francés, y en otros muchos de la imitada o plagiada por los franceses, según la propia Bibliothèque reconoce.

Tras los dos primeros volúmenes de la colección, dedicados a las novelas griegas y latinas, en el tercer tomo (premier volume, tome 3, 216) se dice que ha llegado el momento de aproximarse a los tiempos modernos, "à l'Europe Romanciére": en la colección se harán extractos de las novelas europeas, que irán precedidos de algunas reflexiones sobre el genio y el carácter de la nación tratada, porque este género “tout frivole qu'il est, caractérise peut-être mieux l'esprit de chaque nation qu'aucun autre". A continuación, se manifiesta que se seguirá 
un orden en el uso de las riquezas novelísticas europeas. Es decir, asignarán un rango a cada nación, "en employant leurs productions. Cet ordre nous est inspiré par la justice. Nous pensons que les Espagnols doivent avoir le pas sur tous les autres peuples étrangers, par le caractère, par l'abondance et par l'ancienneté de leurs fictions". Y efectivamente, España es la primera de las naciones modernas que ocupa el interés de esta excelente colección.

La Bibliothèque (8) reconoce que España es una nación orgullosa por naturaleza, muy valiente (courageuse), galante y voluptuosa, bien dispuesta para los celos, con un clima caliente (brûlant), cuyo ardor da más actividad a sus cualidades estimables, y más fuerza a sus pasiones; una nación de este tipo parece hecha para proporcionar al género novelesco más héroes y autores que ninguna otra. La nación española - continúa - ha aprovechado en este sentido todas sus ventajas. Si ella no ha inventado todos los géneros de novelas, los ha perfeccionado todos, y se ha ejercitado en todos con el mayor de los éxitos. Su lengua le es favorable; es noble, sonora y se presta fácilmente a las inflexiones que expresan la ternura. La poesía española, sea heroica o galante, no tiene necesidad de buscar sus expresiones fuera del lenguaje ordinario.

Se necesitaría mucho espacio para transcribir aquí los innumerables y entusiastas elogios que los redactores de la Bibliothèque dedican a la narrativa española. Por sus páginas desfilan auténticos panegíricos de los diversos tipos de novelas españolas: de caballerías, históricas, de amor, políticas y morales, cómicas y satíricas, picarescas, novelas cortas, etc. Asímismo, se subrayan las innumerables deudas que los franceses tienen con España en este género, que a veces traducen, otras imitan y otras plagian de los españoles.

Por otra parte, cuando los críticos franceses enjuician el teatro español, señalan como su principal defecto la inobservancia de las reglas clásicas, sobre todo la mezcla de géneros y las infracciones en torno a la regla de las tres unidades. Pero la predisposición de los medios franceses que estudiamos es tan favorable a España que incluso en este terreno están dispuestos a matizar sus principios clasicistas.

En todos estos periódicos hallamos enfáticos elogios al teatro de Lope, Calderón, Moreto, Guillén de Castro, Rojas, Solís, Matos Fragoso, Bances Candamo, etc. Asimismo, subrayan los beneficios que resultarán para la literatura francesa con las traducciones al francés de 


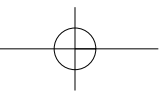

obras dramáticas españolas. Todos reconocen que cuando el teatro francés estaba naciendo, el género dramático ya estaba muy desarrollado en España, por ello los autores galos bebieron frecuentemente de los dramas españoles. Igualmente reconocen que en los tiempos de Corneille y Scarron los franceses construían sus obras siguiendo el gusto español: cuando Molière y Corneille pusieron las bases del teatro francés, no dudaron en tomar prestados de los españoles los materiales necesarios para su construcción. Algunos añaden que gracias al estudio de los antiguos y de los españoles, el teatro francés ha superado al de sus vecinos españoles. Puede leerse también que todavía en el XVIII los autores franceses pueden seguir enriqueciéndose con la lectura del teatro español del XVII. A veces se sostiene que, en contra de lo que se cree en Francia, el teatro español de las últimas décadas del XVIII goza de muy buena salud.

En general, se reconoce al drama español capacidad de invención, genio, riqueza de asuntos, buena pintura de caracteres, comicidad, imaginación brillante y fecunda, habilidad para atraer la atención del espectador, talento para hallar intrigas complicadas y el mejor desenlace, etc. Se considera injusto juzgar el teatro de los españoles según las normas de Boileau. Algunos aconsejan a los autores franceses que lean el teatro español, entre otros motivos porque de él podrán extraer nuevos argumentos para sus obras.

\section{ReDes. Ideología}

Sosteníamos que los juicios de cualquier autor sobre las aportaciones culturales de otro país estaban determinados esencialmente por tres elementos: nacionalismo, canon e ideología. Acerca de esta última, la actitud y la opinión de los "philosophes" franceses sobre España fueron predominantemente negativas. El motivo principal de tan adversa predisposición fue su idea de una España fanática, inquisitorial, intolerante y enemiga del progreso. Ello determinó sus juicios y su falta de interés por conocer el legado español. Sus prejuicios ideológicos obstaculizaron un verdadero acercamiento a la cultura española para, llegado el caso, revisar o puntualizar sus tan negativas estimaciones sobre todo lo relacionado con España. 
Pero, por otra parte estamos hablando de una corriente de opinión francesa favorable con España. Con los datos de que disponemos, sabemos que ninguno de los medios periodísticos favorables a España fueron políticamente cercanos a los philosophes. Sin embargo, no compartieron tampoco la orientación reaccionaria de los antiphilosophes. No todos poseyeron idéntica ideología política, pero sí podemos afirmar que en su mayoría fueron reformistas, moderadamente contrarios al Antiguo Régimen, aunque también a la "secta filosófica". Y sabemos que en cierta medida algunos coincidieron ideológicamente con los enciclopedistas y militaron en la masonería.

La posición política de todos ellos, progubernamental, explicaría decisivamente su buena disposición con respecto a España, en sintonía con los intereses diplomáticos de Francia, aliada de España durante gran parte del siglo. El hecho de dirigir periódicos cuyo contenido implicaba la necesidad del conocimiento de la cultura extranjera completaría su posición. Por otra parte, su oposición a los "philosophes" pudo empujarles a discrepar con ellos también en la cuestión sobre España. Asimismo, sus intereses y gustos personales terminarían de explicar su ubicación proespañola.

La excepción conservadora estaría constituida por el periódico jesuita Mémoires de Trévoux (1701-1767). Pero su dogmatismo religioso y su defensa de la monarquía están acompañados frecuentemente del apoyo al progreso de las artes y las ciencias. Por ejemplo, cuando los memorialistas reseñan un libro - ya citado - sobre filosofía especulativa y experimental y subrayan positivamente la llegada a España de la "nouvelle philosophie" o la ponderada admiración española por Newton y por la física. Asimismo, en las Mémoires son abundantes las reseñas de libros de Feijoo y los elogios a su empeño por acabar con las supersticiones en España.

Hagamos un rápido repaso ${ }^{9}$ al resto de defensores de la imagen de España, en cuyas publicaciones podemos comprobar una clara posición reformista, así como una decidida oposición al fanatismo religioso, a la superstición y a la intolerancia. François Arnaud (1721-1784) fue entre 1760 y 1762 director del Journal étranger (1754-1762), ${ }^{10}$ en co-

\footnotetext{
${ }^{9}$ La mayor parte de estos datos biográficos proceden de las entradas sobre Arnaud, Fréron y Bricaire de la Dixmerie del Dictionnaire des journalistes, de Jean Sgard (1999).

${ }^{10}$ Este periódico tuvo varios directores, entre ellos Prévost (entre febrero y agosto de 1755), Fréron (de septiembre de 1755 hasta septiembre de 1756) y Arnaud (entre
} 
laboración con su amigo Jean Baptiste Suard. Entre 1764 y 1766 dirigió la Gazette littéraire de l'Europe (1764-1766) y después la Gazette de France. En 1777 aparece el Journal de Paris, donde colabora con numerosos artículos. "Il était l'ami des philosophes" (Sgard 1999: 21-23): cuando dirigía la Gazette littéraire tuvo un fuerte enfrentamiento con el arzobispado de París. Resulta que "ce Journal déplaisait aux dévots pour son approche trop philosophique". Los teólogos encontraron en él proposiciones "répréhensibles" que desvelaron en un escrito de denuncia. Los autores de la Gazette littéraire encargaron a su amigo el abate Morellet que respondiera al ataque de los teólogos. Morellet compuso un pequeño folleto anónimo que dio a conocer a Voltaire, muy interesado en este periodico donde escribió numerosos artículos. Voltaire mandó imprimirlo. "Les conséquences auraient pu être très graves pour Arnaud et Suard, cependant ils ne furent pas poursuivis par le pouvoir".

Elie Fréron (1718-1776), de personalidad muy independiente, fue admitido en 1744 como "franc-maçon" en la logia de l'Union de Procope. Desde 1750 "il s'ouvre a toutes les influences étrangères" (Sgard, 1999: 414-417). Luchó a favor de la "saine littérature", fundada en la naturaleza y en los grandes modelos, "pour l'honneur des poètes; contre le bel esprit et le superficiel, contre Voltaire". Entre 1755 y 1756 dirigió el Journal étranger. L'Année littérairee (1754-1790), uno de los más importantes periódicos franceses del XvIII, fue creado en 1754 por Fréron, que lo dirigió hasta 1775; suspendido varias veces, sobrevivió a los ataques de los filósofos. Fue protegido por altos miembros de la monarquía y la aristocracia, así como por sus hermanos masones.

En 1752 polemizó con los enciclopedistas: Fréron, "qui au fond partage leurs idées et vise le même public, dénoncera surtout leurs manoeuvres". Contribuyó a acreditar en la opinión pública la existencia de un partido de filósofos organizados. Defendió la "filosofía práctica", la suya, contra la ideología subversiva, la de ellos, que calificará de

enero de 1760 y septiembre de 1762). Véase el artículo de Pageard (1959), que relaciona las entradas sobre España aparecidas en el Journal Étranger.

${ }^{11}$ Van Tieghem (1917) estudia la presencia en este periódico de distintas literaturas europeas. Sin embargo, presta escasa atención al caso español y no es exhaustivo en su relación de entradas sobre España. Sí lo es, por el contrario, Dante Lenardon, que publicó unos utilísimos índices de este periódico (1979). 
"philosophisme". Mantendrá un duelo con Voltaire, que afectará a L'Année littéraire. El año 1760 señala el punto más alto de la batalla entre Fréron y los filósofos. Fréron se cree acosado por un complot filosófico y defiende a Rousseau. Fue ardiente defensor del trono y del altar, contra los filósofos y enciclopedistas. Pero su posición progubernamental no le impidió criticar los abusos del Antiguo Régimen y de proponer reformas fiscales, sociales y económicas para mejorar la suerte de los campesinos franceses. "Quoique Voltaire ait pu dire de lui, il a un esprit réformateur". Su pecado fue criticar a los filósofos en general y a Voltaire en particular.

Nicolas Bricaire de la Dixmerie (1731-1791) fue miembro de la sociedad masónica de los "Neuf-Soeurs" (Sgard, 1999: 115). En 1779 escribió una "Memoria" de dicha logia y, también ese año, pronunció un elogio de Voltaire. Trabajó en varios periódicos: L'Observateur Littéraire, Mercure de France, Avant-Coureur. Dirigió L'Espagne littéraire ${ }^{12}$ (1774). Trabajó también en la Bibliothèque universelle des romans. El prologuista de Lettres sur l'Espagne (Bricaire de la Dixmerie, 1810), que se presenta como C.P., prologa este libro con una elogiosa biografía de Dixmerie. Dice que no fue partidario de la Revolución francesa, y no porque perdiera su pensión en el Mercure a consecuencia de ella, sino porque era muy sensible ante la sangre y las atrocidades que vio. Añade que fue, sin duda, un filósofo. Dixmerie murió pocos días después de que Pancoucke, dueño del Mercure, cerrara el periódico y retirara su salario al propio Dixmerie.

J. Fr. Bourgoing, otro de los autores citados en este trabajo, fue embajador en España en los años 1792-1793. Poseyó un pensamiento político indudablemente ilustrado. La lectura de su Tableau demuestra su posición muy crítica con la práctica de la tortura en España, con la Inquisición, con la extremada riqueza de clérigos y monjes, con el fanatismo religioso y sus seguidores, etc.

Las buenas relaciones entre los tres periódicos citados (Journal étranger, L'Année littéraire y L'Espagne littéraire) permiten hablar de una

${ }^{12}$ Se publicó solo durante 1774. Su único director fue Nicolas Bricaire de la Dixmerie. En 1810 apareció el volumen Lettres sur l'Espagne (Bricaire de la Dixmerie 1810), donde se recogen muchos de los artículos aparecidos en aquel periódico y donde el prologuista, C.P., manifiesta que Dixmerie le pidió días antes de morir que publicara en libro los artículos que él había escrito para L'Espagne littéraire, los cuales el propio Dixmerie le señaló. 
"red" periodística francesa interesada en dar a conocer en Francia la cultura española: sus respectivos editores se conocen, se aprecian y comparten su estima por el legado cultural español. Veamos una muestra muy significativa.

En L'Année littéraire de 1774 (122-142), bajo el título de "L'Espagne littéraire. Année 1774; premier volume de 360 pages", aparece una carta sin firma, dirigida al director del periódico (Fréron). El autor de la carta (muy probablemente Arnaud, ya que menciona su época como director del Journal Étranger) se felicita por la reciente aparición del periódico titulado L'Espagne littéraire, a cuyo director, Bricaire de la Dixmerie, dedica notables elogios: este periódico, dice Arnaud a Fréron, es uno de los mejor hechos y de los más interesantes que se puedan imaginar. Tras diferentes alabanzas, manifiesta que M. de la Dixmerie, escritor estimable "à tous égards", y cuyo nombre es muy apropiado para dar valor a una empresa literaria, es el redactor de los materiales que entran en la composición de este periódico.

A propósito de la oportunidad y la conveniencia de este periódico, ocupado exclusivamente de las cosas de España (y en pequeña medida de Portugal), y de la necesidad de dedicar un espacio monográfico a España, dice Arnaud que cuando él estaba encargado de la dirección del Journal étranger, encontraba el proyecto de ese periódico muy bello, pero su objetivo era demasiado amplio. Es decir, era imposible dar noticia en doce pequeños volúmenes por año de la literatura del mundo entero. Es mejor, dice, que para dar una idea de las riquezas literarias de los diversos países de Europa, haya un periódico para cada nación. Es lo que va a hacer L'Espagne littéraire, cuyos autores se proponen dar a conocer las "Mémoires" de las academias españolas y portuguesas, los escritos de los literatos ligados a estas academias (por resúmenes y análisis, o por traducciones completas), extractos sobre la vida de autores muertos $\mathrm{u}$ hombres célebres que han honrado a estas dos naciones. Además, este periódico se ocupará de diferentes ciencias: moral, jurisprudencia, física, etc. etc., y particularmente de lo que concierne a las bellas letras, es decir, el teatro, las novelas, las "piezas fugitivas" y otras obras de gusto, tanto en prosa como en verso. Por otra parte, añade, sus autores anuncian que en cada número habrá una lección sobre la lengua española, "leçon fort abrégée", pero clara, precisa, propia para facilitar el estudio y el conocimiento de esta lengua. 
De esta manera, el que fuera director del Journal étranger, Arnaud, escribe al director de L'Année litéraire, Fréron, para congratularse de la aparición del periódico L'Espagne littéraire, a cuyo director, Bricaire de la Dixmerie, dedica grandes elogios. En la carta se advierte la voluntad de los tres periódicos - que se publicaron entre los años cincuenta y setenta - para dar a conocer en Francia la producción cultural española de los últimos tiempos. ${ }^{13}$ En los años anteriores esa tarea de difusión fue asumida por las Mémoires de Trévoux.

En el volumen de L'Année de 1775 hay otra carta (nuevamente de Arnaud) sobre L'Espagne littéraire, referida esta vez al tomo II (1774: 29-52) de dicha publicación. Su autor menciona aquella primera carta y continúa diciendo que los artículos que aparecen en el periódico de Dixmerie contribuyen a "jeter le plus grand" luz sobre la historia actual de las costumbres y la literatura de España, pueblo estimable que, hasta el presente, no había atraído demasiado nuestra atención.

A continuación pasa revista al contenido de este volumen, donde dice que se encuentran excelentes extractos de obras españolas, traducciones de poesías, etc. Reproduce algunos fragmentos y cita a Feijoo. Acaba con la valoración de que hay pocos periódicos tan instructivos y agradables como este y de que el trabajo de sus redactores merece el apoyo más grande, tanto por su objeto como por la manera en que este se lleva a cabo.

\section{Nacionalismo. Diplomacia política}

No puede negarse la vigencia en la Francia dieciochesca de numerosos tópicos antiespañoles, muy ligados a las lecturas nacionalistas entre países. Tomemos como ejemplo el libro Lettres juives, ou correspondance philosophique, de Jean Baptiste Boyer d'Argens, publicado en 1738. En él se resumen todos los tópicos antiespañoles, algunos con una base real y otros procedentes de una manipulación política de siglos.

\footnotetext{
${ }^{13}$ Françoise Étienvre (1973: 320) señala que en otro periódico de la época, L'AvantCoureur, Anne-Gabriel Meusnier de Querlon (amigo de Dixmerie) se felicita por la aparición de L'Espagne littéraire, que viene a remediar el hecho de que España sea para los franceses "plus étrangère qu'aucune autre [nation] et la plus ignorée en France".
} 
Es incontestable, así pues, que existen numerosos textos franceses que acreditan una lectura muy negativa de España: la crítica de su historia político-militar, de la colonización americana, de la Inquisición, de su resistencia al progreso, los tópicos acerca del carácter y costumbres de los españoles, etc. Junto a críticas fundadas, es inobjetable que muchas de esas opiniones antiespañolas estaban desprovistas de una base sólida. Son muchos los juicios franceses que muestran un gran desconocimiento sobre España. En muchos casos es evidente, además, el escaso interés por una mejor información al respecto. Los españoles son conscientes de ello. Escribía Quintana en el periódico Variedades: "la ignorancia y la inconsideración con que por lo general hablan los franceses de nuestras cosas, son males incurables en ellos". Fundados en muchos errores, dictaminan "resultados políticos, morales y literarios" referidos a España (Variedades de ciencias, literatura y artes 1803: I, 248-249). También algunos franceses advierten este hecho: decía Bricaire de la Dixmerie en L'Espagne littéraire (1810: carta I, 59-65) que va a intentar conocer un país, España, que parece a los franceses tan extranjero como la China, a pesar de la poca distancia que los separa.

No es este el lugar para tratar esos textos franceses demostrativos de ese nacionalismo despreciativo con lo español. Solo me detendré, muy sintéticamente, en los textos de autores y periódicos favorablemente predispuestos con España, para mostrar que, cuando se suscitan comparaciones entre países, esa positiva disposición también se ve interferida - aunque no anulada - por actitudes nacionalistas.

La buena disposición hacia España de las Mémoires de Trévoux se vio entorpecida a veces por cuestiones de patriotismo. Prueba de ello es la reseña que se dedica (1743: XLIII, 478-492) al "Paralelo de lenguas" del Teatro crítico de Feijoo. Esta recensión intenta conciliar el nacionalismo francés con una actitud contemporizadora con España y elogiosa con sus autores, en este caso con Feijoo.

Para empezar, los padres de Trévoux enjuician favorablemente a Feijoo como imparcial mediador entre los dos bandos existentes entonces en España: "Toujours sincère et toujours raisonnable, notre Espagnol zélé refute ici deux erreurs qui régnent en Espagne sur la langue françoise; les uns la méprisent trop, les autres l'estiment trop". Feijoo "combat ces deux excès, $1^{\circ}$ ) il venge la langue françoise de ceux qui la méprisent, et leur en fait connaître le prix, $2^{\circ}$ ) il rend a la langue castillane les avantages qu'on lui ôte". 
Pero después se transcribe la opinión de Feijoo de que los franceses tienen una pronunciación más dulce y los españoles, más fuerte; la lengua francesa es más "coulante", la española más "frappante". Y Feijoo concluye a favor del castellano, porque "c'est qu'une force mâle est une qualité plus noble, qu'une douceur efféminée". El nacionalismo de Feijoo es respondido por Trévoux con idéntico nacionalismo, esta vez jugando a la defensiva y cargando las culpas a un tercer país, para no enfadar a los españoles: "Le P. Feijoo me le pardonnera si je dis qu'il n'a pas une idée trop juste de la Langue Françoise, qu'il prend une langue pour une autre, l'italienne pour la françoise. L'italienne peut avoir ce défaut, mais la français ne l'a point". Esta ama la propiedad, y "elle ne hait rien tant que l'affectation [...], elle n'a point ces diminutifs fades, ni ces terminations doucereuses, que la langue italienne aime tant", el francés tiene dulzura, pero natural, no artificial, una dulzura que se parece a la del griego, y que nunca fue una dulzura afeminada.

Continúa el reseñador afirmando que el estilo del español es más ampuloso, pero no más armonioso que el francés. Y no es cierta la idea de Feijoo de que la lengua castellana es tan fecunda como el mismo latín, y que ninguna otra lengua, a excepción del griego, la iguala. Dice el reseñador que Feijoo subraya tanto la riqueza del castellano para reprochar la pobreza del francés, pero está equivocado, porque la lengua francesa es más rica y más abundante de lo que Feijoo piensa, y pone ejemplos. Concluye el periódico francés parafraseando al Padre Porée: lo que señala definitivamente la gloria de la lengua francesa es que se habla en todas partes; se habla en España, Inglaterra, Alemania, Italia, en todas las cortes de Europa; se extiende por todos los sitios; la lengua castellana "n'a pas fait encore tant de conquêtes". Como vemos, la mejor predisposición -de Feijoo ante Francia y de las Mémoires ante España - se tambalea ante las servidumbres nacionalistas.

También L'Année littéraire fue un periódico bien predispuesto con España. Pero, igualmente, su actitud favorable se atempera cuando los españoles vierten contra Francia acusaciones que considera injustas. Se advierte en la recensión sobre la "Dissertation sur les tragédies espagnoles" (1754: tome III, lettre II, 27-41). Su anónimo autor reseña concretamente una traducción francesa del Discurso I de Montiano así como de su tragedia Virginia. El recensionista es demoledor con las ideas del discurso, así como con la tragedia que lo acompaña. Critica a 
Montiano por suscribir la opinión de Nasarre de que "los españoles tienen más comedias perfectas y según las reglas que los franceses, los italianos y los ingleses juntos". Afirmación esta que al reseñador le parece, justamente, una fanfarronada. El reseñador critica después que Montiano quiera adjudicar a los españoles ser los primeros en escribir tragedias modernas, cuando los ejemplos que aduce son simples traducciones del teatro griego: el hecho de que Montiano cite estas dos obras como "monuments glorieux pour la littérature espagnole" demuestra la escasez de tragedias en el teatro español.

Pero a pesar de las críticas a Montiano y al traductor francés, la buena disposición del periódico le determina a reconocer las deudas con España del teatro francés, concediendo, eso sí, la primacía a este último: "Nos Corneilles et nos Molières ont pu sans doute puiser avec succès dans cette source. Mais il y a une grande différence entre imiter avec génie quelques endroits d'un ouvrage, et traduire avec scrupule ce même ouvrage rempli de défauts". Incluso hace algunos elogios a Montiano, quien - dice- merece los más grandes elogios por el vivo deseo de demostrar que en su nación existe amor a las reglas. Además, debe ser elogiado por no limitarse a predicar la práctica del clasicismo: Montiano pasa a la acción escribiendo la Virginia, donde esas reglas están pulcramente observadas, aunque no tan bien como piensa Montiano, según el crítico francés.

La recensión concluye sosteniendo que a pesar de los defectos de la disertación y de la tragedia, estas "anuncian" un hombre de genio, original y conocedor de los buenos modelos, "qui crée par lui-même et qui connoît les bons modèles". Es decir, Montiano es un buen seguidor del clasicismo francés. En la reseña se elogia también al traductor francés por haber incluido un catálogo con noticias sobre los autores de los que Montiano habla en su discurso. Gracias a él - dice - tenemos una noticia adecuada de gran parte de la literatura española, mostrando así el deseo del periódico de poseer una mejor información sobre el legado cultural español.

El Journal Étranger nos proporciona otro ejemplo para este asunto. En el "Prospectus du nouveau Journal Étranger" (1760: janvier) afirma Arnaud que el distinto genio y carácter de los pueblos se ve sobre todo en sus obras y en su lengua. El discurso, centrado en la comparación del italiano, francés y español, realiza variadas y ecuánimes consideraciones sobre los caracteres de cada lengua, y reparte elogios para to- 
das ellas. Tras haber afirmado la "nobleza y elevación" del español, así como su mayor sobriedad y moderación en comparación con el italiano, concluye que Francia dio al francés orden, método, claridad, precisión, y elegancia (XXVII). Estas apreciaciones reaparecieron después en las Variétés Littéraires (1768-1769), también de Arnaud, donde se añade que la lengua francesa "procède comme la pensée et l'observation, la langue française, en un mot, devoit donc nécessairement devenir la langue dominante de l'Europe" (Variétés 1804: I, 18) Es decir, el carácter esencial de la lengua francesa la predestinó para ser la lengua europea principal.

También Bourgoing, tan ecuánime con todas las cuestiones españolas que trata, participa de ese inevitable nacionalismo. Critica, con toda la razón, la desafortunada frase de Nasarre ya citada - que, evidentemente, tuvo repercusión en Francia-, así como a García de la Huerta. De este dice que se pronunció de manera muy severa e injusta - en su discurso preliminar al Theatro español (1785) - sobre obras maestras de la literatura francesa: cómo es posible, se pregunta Huerta y transcribe Bourgoing, que el fuego divino de la poesía pueda animar a gentes nacidas y educadas en tierras "marécageuses", desprovistas de "soufre, de sels et de substances", poco favorecidas por el calor y el sol. De aquí deriva la mediocridad de gran parte de las obras francesas, según Huerta, que sigue con críticas al Cid de Voltaire, a la Atalía y Fedra de Racine, así como a Molière.

Airado contra Huerta, escribe Bourgoing que los extranjeros conocedores de la escena española son quienes deben decidir si "l'aveuglement ou la mauvaise foi a dicté les jugements de cet impitoyable censeur. Mais sans vouloir lui rendre injure pour injure, nous nous bornerons à dire que tous ceux qui ont une apparence de goût, tant en Espagne qu'au dehors, conviennent que toutes les pièces espagnoles, à quelques exceptions modernes près, sont pleines des plus choquantes défectuosités" (II, 389).

Junto a estos moderados desahogos antiespañoles, movidos por su nacionalismo, y también por su gusto clasicista, Bourgoing no deja de elogiar a Huerta y alaba la actuación de los españoles neoclásicos: los españoles modernos se ocupan de la regeneración de su teatro, desde hace mucho tiempo fecundo en producciones "qu'avouait le génie, mais que réprouvait le bon goût". Algunos de sus autores han estudiado con fruto los buenos modelos y el público es cada vez más capaz 
de apreciarlos (II, 382). Termina reconociendo las deudas del teatro francés con el español: su influencia en Molière y Corneille. Ecuanimidad y desprejuiciamiento, pero también mesurado nacionalismo cultural. Y, por supuesto, la conciencia de que los franceses eran los depositarios del buen gusto en cuestiones de teatro y estéticas en general.

Por otra parte, es innegable la influencia que la diplomacia política tiene en el imaginario nacional y en el nacionalismo cultural. Si dos países mantienen una alianza política, los autores y medios --sobre todo si son progubernamentales - atemperarán su inevitable nacionalismo. El debate francoespañol que tuvo mayores repercusiones en el ámbito político y cultural fue el provocado por el célebre artículo de Masson de Morvilliers en la Encyclopédie Méthodique. En aquel debate se advierte de manera paradigmática la imbricación de cultura y política; cómo una cuestión puramente cultural puede tomar una u otra deriva sociopolítica dependiendo del estado de las relaciones diplomáticas entre países. Las reacciones a dicha publicación fueron variadas, pero muchas de ellas - así como las consiguientes decisiones políticas - estuvieron determinadas por la alianza francespañola de aquel momento. Si la relación entre los dos países hubiera sido otra, las reacciones de los medios políticos y culturales también habrían sido otras.

En el mundo cultural francés bien predispuesto con España hubo respuestas moderadas y ecuánimes, como la de Bourgoing, quien dice que Masson prodigó sin mesura las más graves inculpaciones a una nación que mantiene estrechas relaciones con Francia. Tras resumir los episodios del caso, Bourgoing - diplomático francés- censura al gobierno español por liderar la respuesta a Masson: así dio todavía más publicidad al asunto. Tras las críticas a la actuación española en este asunto, y quizás para compensar esas censuras, Bourgoing enumera para los lectores franceses la versión española sobre la aportación que España ha hecho históricamente a Europa, motivo desencadenante de aquel conflicto cultural y diplomático. Critica a Cavanilles por su exagerada apología de España, "il était encore plus prodigues en éloges que l'auteur français ne l'avait été en reproches graves"' (II, 308), y además añade: "A-t-il rempli son but?" (II, 313). Bourgoing no responde a su pregunta. 
Si Bourgoing adopta en el asunto un papel equidistante entre las versiones que minimizan, una, o maximizan, otra, el valor del legado español, L'Année littéraire (1784: VI, 304-317) se decanta definitivamente a favor de la apología española escrita por Cavanilles y manifiesta explícitamente un dato muy significativo en la cuestión que nos ocupa: Masson fue la voz de los "philosophes". El periodista sostiene que los franceses no comparten las opiniones de Masson, "qu'à l'exception de quelques philosophes, dont cet ecrivain s'est rendu l'écho. Tous [los franceses] sont pénétrés d'estime pour les Espagnols et renden hommage" al mérito de una nación que "est devenue comme notre alliée". Evidentemente es una opinión interesada: ni todos los franceses estimaban a España, ni Masson era portavoz de los philosophes: además de que no existen datos sobre una posible relación entre ambos, no pueden atribuirse a todos los philosophes franceses unas opiniones tan extremas como las manifestadas por Masson. En cualquier caso, es interesante que el periódico interprete las opiniones de Masson como representativas del parecer de los philosophes.

Veamos otro ejemplo, en este caso perteneciente a la primera mitad del siglo y relativo a la polémica sostenida por Luzán y los diaristas de Trévoux, cuando los franceses acudieron precisamente a la alianza político-militar entre Francia y España para solventar sus diferencias y para subrayar que los dos países navegaban en un mismo barco. Es el caso de la reseña que en 1747 (XCVII, VIII, 1432-1441) publican las Mémoires de Trévoux sobre la Carta latina de Ignacio Philalethes a los P.P. de Trevoux (Zaragoza, 1743), ya citada. Se trata del texto que escribió Luzán para protestar contra las opiniones expresadas anteriormente por los memorialistas, en las que se desmerecía a España. El memorialista afirma que lo que las Mémoires dijeron entonces es que en Francia se tiene tendencia a pensar que en España no se hace nada en ciencias digno de la atención francesa. Pero, añade ahora el periodista, las Mémoires de Trévoux no tomaban partido por esa opinión, sino que la consideraban un prejuicio.

Se lamentaba Luzán de que no se reconociese el mérito literario de España. El de Trévoux le responde que esa rivalidad pudo existir hace cien años, pero ahora, cuando hay una estrecha alianza entre las dos ramas de los Borbones, los franceses miramos, dicen las Mémoires, la gloria de España como un bien que nos interesa, que nos atañe, como una especie de herencia que queremos defender con la pluma y la es- 
pada. "Les François et les Espagnols semblent n'avoir maintenant qu'un seul et même intérêt. Les Littérateurs des deux Nations doivent être aussi unis que leurs guerriers; et si les armes de ceux-ci bravent avec avantage les efforts de l'Europe conjurée, ceux-là peuvent au moins balancer les Littérateurs des autres Nations, et établir sur le Parnasse l'équilibre qu'on cherche depuis un siècle à introduire dans le Systeme de l'Europe". Aliados en la espada y aliados en la pluma. El nacionalismo debe desaparecer -o convertirse en un nacionalismo francoespañol- en estas ocasiones históricas en que dos naciones aliadas se convierten en una sola.

\section{CANON. GuSTO FRANCÉS Y ESPAÑOL}

Los juicios franceses sobre la literatura española estuvieron condicionados por el canon entonces hegemónico en Francia, el clasicista, el "francés". Es una estética defendida como propia, particularmente francesa. Quienes no la comparten son vistos, de manera más o menos explícita, como gente de gusto poco refinado. El gusto barroco es criticado por los clasicistas franceses, que censuran gran parte de la literatura española, la barroca, donde la imaginación se desborda y las reglas se incumplen.

Escribía Bourgoing que la diferencia de gusto entre los españoles y franceses se basa en sus diferentes lenguas y en sus distintas actitudes ante la imaginación y el juicio: los españoles encuentran nuestras poesías, dice Bourgoing, "froides et timides": "acostumbrados a la exageración y la redundancia, no pueden apreciar el mérito de la justeza y la precisión" (II, 372).

Lo más frecuente en los autores franceses es la minusvaloración de toda obra que no sea fiel a la "estética francesa", al clasicismo, cuyas reglas deben cumplirse inexorablemente. Los franceses más moderados en este asunto pueden llegar a ser permisivos con el incumplimiento de algunas reglas, pero no con las faltas contra "la Regla": es el caso, por ejemplo, del Journal Étranger (1760, janvier) de Arnaud, que en el "Prospectus du nouveau Journal Étranger" parece defender un punto de vista intermedio entre los universalistas y los relativistas. Sin embargo, su distinción entre Regla y reglas manifiesta claramente su 
adscripción universalista: "Il ne faut pas confondre la Règle avec les Règles". Obviamente, el depositario único de la Regla es Francia.

Podría decirse que el nacionalismo llevado al terreno de la estética exige a los franceses la defensa del clasicismo, asunto sobre el que existe un gran consenso nacional en Francia. El nacionalismo estético español requería la defensa del barroco, pero en la España del siglo XVIII no existía en esta cuestión el consenso que mostraban los franceses, dada la división de los españoles en clasicistas y barrocos. Los clasicistas españoles sostenían que el mejor patriotismo español es el que preconizaba la adhesión al gusto europeo, el francés, el clasicista.

Excepcionalmente existen autores franceses, como Mercier, que con una lúcida autocrítica desenmascaran la manipulación del concepto de buen gusto que cada nación lleva a cabo en su propio provecho. Los pueblos civilizados - dice - relacionan el "gusto" con lo que suponen que es lo más perfecto de sus propias producciones artísticas. El orgullo de cada nación ha utilizado esta palabra en su propio provecho; cada nación la aplica para proscribir con mayor autoridad aquello que no entra en sus usos, o lo que choca con sus hábitos (1778: 71).

Mercier critica las "reglas sagradas" del teatro francés y el rechazo del teatro bárbaro, el español, el de Shakespeare... Y arremete contra "los tiranos de la República de las Letras" que imponen esas reglas, sobre quienes se pregunta si no serán ellos los bárbaros, que rechazan a escritores que nunca han leído, que no entienden, que no quieren entender, que se burlan de otras naciones cultas. Porque, esto es exactamente - dice - lo que se ha hecho en Francia cuando se ha examinado a Shakespeare, a Lope de Vega, a Calderón. En fin, Francia, sostiene, es una nación que no se molesta en sospechar que el arte es susceptible de otras formas (1778: 137-138).

Pero, como digo, lo más frecuente en los autores franceses es la asunción y defensa sin fisuras del gusto neoclásico. Por ello les resulta muy difícil conciliar este principio con la defensa de literaturas extranjeras ajenas a "la Regla". Esto es lo que sucede a esos autores y periódicos tan bien predispuestos con España, cuyos juicios sobre obras españolas de gusto barroco difícilmente pueden llegar a ser positivos. Su deseo de elogiar la literatura española es difícilmente conciliable con sus principios estéticos.

El moderado Journal Étranger nos sirve como paradigma ilustrativo de las citadas opiniones de Mercier. En la presentación de Fréron a los 
lectores de este periódico, se dice ("Avertissement de M. Fréron" 1755: $125-148$ y 149-160) que Europa debe ser vista hoy como una gran república literaria. El objetivo de este periódico es recoger todas las riquezas literarias dispersas por el mundo entero. Porque a pesar de que existe un "beau universel", también hay una belleza local, muchas bellezas locales, ya que las costumbres de los países son distintas. Pero este reconocimiento de la diversidad, del relativismo estético, es solo una apariencia, porque, en realidad, el norte del periódico será, según dice Fréron, el de restaurar ese gusto universal, basado en la razón y en la naturaleza y perdido en algunas partes.

Sin embargo, lo que me importa subrayar en este apartado es que, a pesar de ese dogmatismo francés en cuestiones de estética, existen autores y periódicos franceses que muestran una buena disposición y una gran comprensión con el "gusto español", intentando, a veces, conciliar lo inconciliable.

Las Mémoires de Trévoux conceden una especial atención a las letras españolas, sobre todo en los años cuarenta y cincuenta, cuando el debate entre clasicismo y barroco adquiere un gran relieve entre los autores españoles. Los memorialistas franceses defienden, como la generalidad de los letrados galos, el gusto clásico y, consecuentemente, elogian las publicaciones españolas que se adhieren a esta estética.

En una reseña de 1738 al Extrait de plusieurs pièces du théatre espagnol (1737), de Du Perron de Castera (Mémoires de Trévoux 1738: XXXVIII, 1834-1846) hallamos una buena muestra de la adscripción clasicista del periódico, pero al mismo tiempo comprobamos que no desean molestar con sus juicios estéticos a los vecinos españoles. Tras defender un gusto universal, y quizás como prueba de su buena inclinación hacia la literatura española, sostiene el reseñador que el buen gusto puede encontrarse en distintos lugares, lo cual literalmente significa que no se encuentra solo en Francia. Efectivamente, puede hallarse también en España, pero, tal y como defiende la conclusión final, no en su literatura barroca y sí en su literatura clasicista, en la literatura que se adapta a la estética francesa: "nous ne voulons pas dire que tous le goûts soient bons, et que le goût en géneral soit arbitraire. Il n'y en peut avoir qu'un bon; indépendant des climats; des temps et des moeurs. C'est un point decidé par la nature...". Vemos así, de qué manera este periódico quiere conciliar su pensamiento estético clasicista, universalista, con una actitud amistosa con España. El resultado es un 
discurso ambiguo, aparentemente equilibrado y contemporizador, pero al borde de la contradicción.

Existe en los autores que estamos manejando una moderación ante España que casi llega a justificar las "infracciones" dramáticas de los españoles, o que duda sobre la conveniencia de atenerse estrictamente a las reglas, como hacen los franceses. Algunos concluyen que debe llegarse a un punto intermedio entre la relajación y el rigor excesivo, o bien estiman que cada nación puede elegir legítimamente su propia opción. ${ }^{14}$

Cuando los autores franceses enjuician el teatro español, señalan como su principal defecto la inobservancia de las reglas clásicas, sobre todo la mezcla de géneros y las infracciones en torno a la regla de las tres unidades. Pero la predisposición de los citados críticos franceses es tan favorable a España que incluso en este terreno están dispuestos a matizar sus principios clasicistas. Ejemplo de ello es la reseña de L'Année littéraire (1771: tome septiéme, 3-52) sobre el Theâtre espagnol de Linguet.

Los clasicistas franceses criticaban el teatro español porque sus obras no eran ni tragedias ni comedias, sino tragicomedias. Quizás para justificar la práctica española, el reseñador explica que la palabra "comedia" en España se toma "indiferentemente para el título genérico de todas las piezas de teatro y responde también a la de "drama" entre nosotros". Aunque esto sea cierto, también lo es que los españoles distinguían pefectamente la tragedia de la comedia, motivo por el que nuestros neoclásicos censuraban tantas obras españolas que bajo el título de comedia o de tragedia eran en realidad tragicomedias.

Pero la benevolencia del reseñador francés no acaba ahí. A continuación intenta justificar las infracciones españolas contra la unidad de tiempo, interrogándose sobre la conveniencia de que en Francia se replantee este asunto. Dice que en España, las obras dramáticas en lugar de estar divididas en actos, lo están en jornadas, "en sorte que la durée de l'action est de trois jours au lieu d'être de vingt-quatre heures". Los españoles defensores del barroco nunca tuvieron esta ocurrencia teórico-literaria para justificar las "infracciones" contra la unidad de tiempo.

\footnotetext{
${ }^{14}$ Como es sabido, el teatro francés del siglo XVIII también buscó fórmulas dramáticas alejadas del clasicismo.
} 
El recensionista francés añade que quizás esta división es, al menos, tan razonable como la nuestra. El ingenio no necesita esfuerzo para introducir "une action qui s'accomplit dans cet intervalle de temps; et l'on ne voit sans cesse les auteurs dans une contrainte puérile pour rassembler dans l'espace d'un jour un tas d'évènements" que muy frecuentemente no podrían suceder en el espacio de tres meses. Y concluye que si la división de los españoles fuera aceptada entre nosotros "nos pièces de Théatre y gagneroient du côté de la vraisemblance".

\section{CONCLUSIÓN}

En conclusión, con este trabajo estoy identificando la existencia en la Francia del siglo XVIII de una importante corriente de opinión favorable a España. Importante porque varios de los periódicos que integran esa corriente figuran entre los principales de la Francia ilustrada.

No se puede seguir sosteniendo la idea de que en la Francia dieciochesca solo existió ignorancia y menosprecio hacia las cosas de España. Posiblemente esa fue la actitud más frecuente en los "philosophes", pero no en autores más moderados políticamente. No estamos hablando, ni mucho menos, de que la corriente proespañola militase en las filas de la "antifilosofía", en la cual posiblemente también existiese una posición proespañola. No; la corriente simpatizante con España que hemos identificado en este trabajo se sitúa mayormente en el terreno político del reformismo ilustrado, cuya posición progubernamental y alejada del rupturismo revolucionario, era sin embargo crítica con las estructuras del Antiguo Régimen, la Inquisición y el fanatismo religioso. Algunos de sus autores eran masones y casi todos podrían considerarse cercanos al enciclopedismo.

Puesto que los periódicos, autores y textos examinados aquí pertenecen al ámbito literario-cultural, su predisposición proespañola se traduce en una defensa del legado literario y cultural español. Pero también se advierte su identificación con el reformismo español de la época, el político y el literario. Este último es el que ocupa un mayor espacio en este trabajo, dado el carácter del corpus de publicaciones estudiado.

Espero haber mostrado, así pues, que en el siglo XVIII francés existió un grupo de intelectuales y medios periodísticos - algunos de ellos 
conectados entre sí, integrantes de una "red" que sufrió los ataques de los "philosophes" - interesados en reabrir o reforzar los canales de comunicación con España, y comprometidos en una interpretación positiva del legado histórico español. Tan positiva como permitían a los autores franceses las servidumbres que suelen interferir en estas cuestiones entre países: el nacionalismo, el canon clasicista francés y, finalmente, la ideología y circunstancias personales de cada autor.

\section{BIBLIOGRAFÍA}

L'année littéraire, ou suite des lettres sur quelques écrits de ce temps. (1754-1790), Paris, Lambert, Pancoucke, Lacombe, Delalain, Le Jay, Mérigot, Crapart. Facsímil: Genève, Slatkine Reprints, 1966-1968.

Bibliothèque universelle des romans (1775-1789). Paris, Chez Lacombe.

BourgoInG, J. Fr. (1807 [1789]). Tableau de l'Espagne Moderne. $4^{\mathrm{a}}$ ed. Paris, Chez Tourneisen. 3 vols. y Atlas.

BRICAIRE De LA DixMERIE, Nicolas (1810). Lettres sur l'Espagne ou essai sur les moeurs, les usages et la littérature de ce Royaume. Paris, Chez Briand. 2 vols.

L'Espagne littérarie (1774). Paris, Chez Lacombe.

Etienvre, Françoise (1973). “España en las Nouvelles de la République des lettres et des arts (1777-1788)", en: Boletín de la Biblioteca de Menéndez Pelayo, 1-4, pp. 319-349.

García CÁrCel, Ricardo (1992), La leyenda negra. Historia y opinión, Madrid, Alianza Editorial.

Journal de Trévoux ou Mémoires pour servir à l'histoire des sciences et des arts (17011767). 265 vols. Ed. facsimilar: Genève, Slatkine, 1968-1969 (67 vols. e índice).

Journal Étranger (1754-1762). Paris/Pissot, Durand/Saugrain le fils.

LenARDON, Dante (1979). Index de L'année littéraire (1754-1790). Genève, Slatkine.

- (1986). Index du Journal de Trévoux (1701-1767). Genève, Slatkine.

López de AbiAdA, J. M./López BernASOCCHI, A. (eds.). (2004). Imágenes de España en culturas y literaturas europeas (siglos XVI-XVII). Madrid, Verbum.,

[MÉMOIRES DE TRÉVOUX], Mémoires pour (servir a) l'histoire des Sciences et des Beaux-Arts (1701-1767), 265 volúmenes. Existe reproducción facsimilar: Genève, Slatkine, 1968-1969 (67 vols.+index).

MerCIER, L. S. (1778). De la littérature et des littérateurs. Suivi d'un nouvel examen de la tragédie Françoise. Paris, Yverdon. Ed. facsimilar: Genève, Slatkine Reprints, 1970. 
PAgeARD, R. (1959). “L'Espagne dans le Journal Étranger (1754-1762) et La Gazette Littéraire de l'Europe (1764-1766)", en: Revue de Littérature Comparée, XXXIII, 3, pp. 376-400.

PÉREZ, Joseph (2010). La leyenda negra. Madrid, Gadir.

SGARD, Jean (dir.) (1991). Dictionnaire des journeaux (Dictionnaire de la presse, 1600-1789). Paris, Universitas.

- (dir.) (1999). Dictionnaire des journalistes (Dictionnaire de la presse, 1600-1789). Oxford, Voltaire Foundation.

VAn Tieghem, P. (1917). L'Année Littéraire (1754-1790) comme intermédiaire en France des littératures étrangères. Paris, Rieder.

Variétés Littéraires (1969). Ed. Facsimilar de 1804. Genève, Slatkine Reprints., 1969: es el facsímil de la edición de 1804. Variétés Littéraires se publicaron originalmente en 1768-1769.

VÁzQuez, Lydia (1997). "Espagne et Portugal”, en: Delon, Michel (dir.). Dictionnaire européen des Lumières. Paris, Presses Universitaires de France, pp. 416-426.

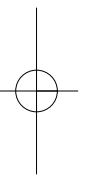


04-checa.qxd 26/09/2012 7:41 Page 138
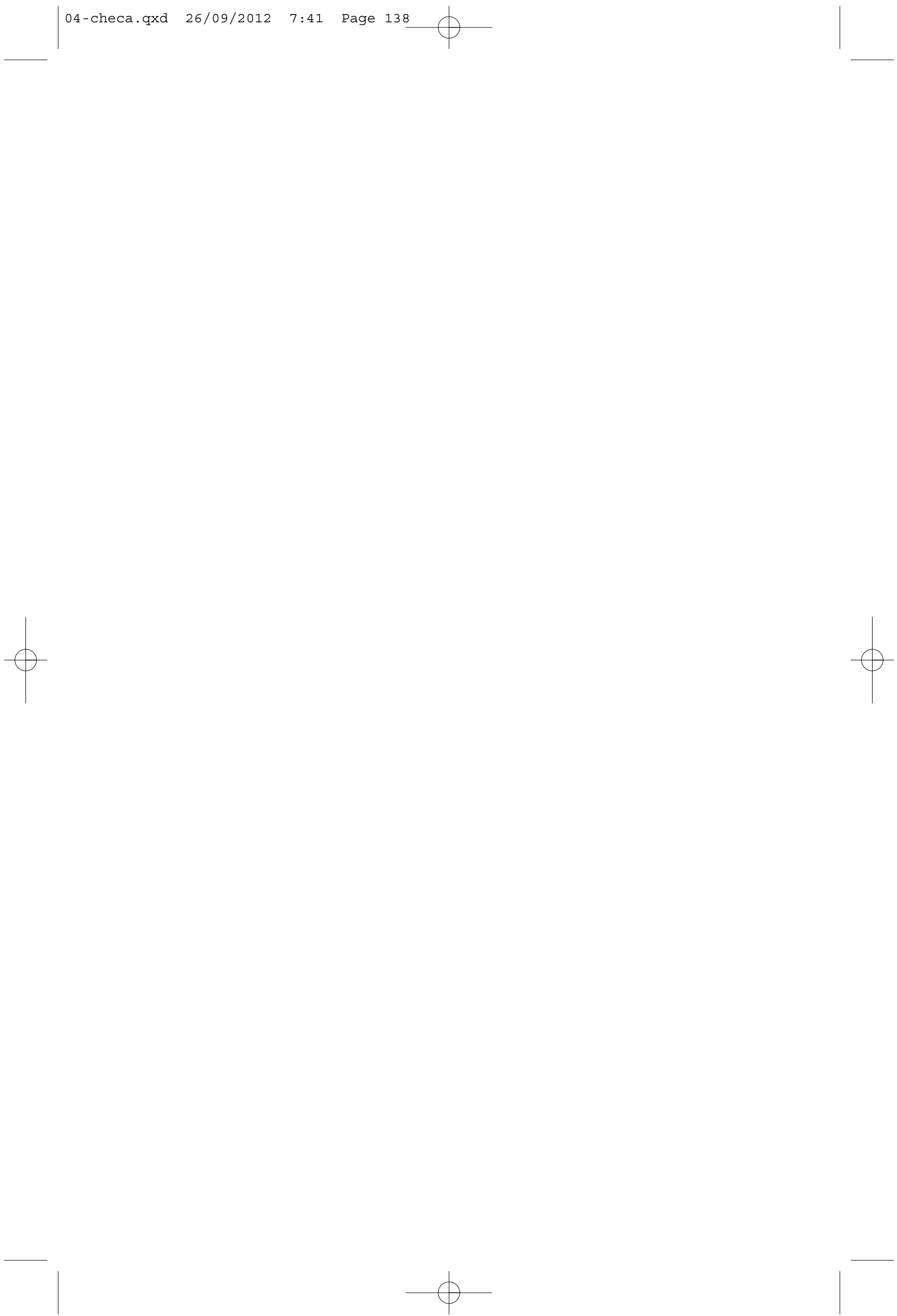